\title{
GINGIVAL MUCOSA PROLIFERATIVE ACTIVITY AND EPITHELIOCYTES APOPTOSIS INDICATORS IN PATIENTS WITH RAPIDLY PROGRESING PERIODONTITIS
}

\section{Svetlana Akimova ${ }^{7 *}$, Natalia Bulkina ${ }^{2}$, Yulia Osipova ${ }^{2}$, Larisa Ostrovskaya ${ }^{2}$, Larisa Zyulkina', Anna Vedyaeva ${ }^{3}$, Valeriy Konnov ${ }^{4}$}

\author{
'Department of Dentistry, Penza State University, Penza, Russia \\ ${ }^{2}$ Department of Therapeutic Dentistry; Saratov, Russia \\ ${ }^{3}$ Department of Dentistry, Sechenov University; Department of \\ Periodontology, Central Research Institute of Dental and Maxillofacial \\ Surgery, Moscow, Russia \\ ${ }^{4}$ Department of Orthopedic Dentistry; Saratov State Medical University, \\ Saratov, Russia
}

*Corresponding Author: cnit@pnzgu.ru

\begin{abstract}
The purpose of the study implied identifying the nature of disturbances affecting proliferation and apoptosis in the epithelium of the gingival membrane in patients with rapidly progressing periodontitis (RPP). Studies have shown specific features of cellular homeostasis disorders manifested through a progressing epithelial proliferation lagging behind their apoptotic activity.
\end{abstract}

KEYW ORDS — periodontitis; rapidly progressing periodontitis; proliferation; Ki-67; Bcl-2; apoptosis

\section{INTRODUCTION}

Practicing dentists come across RPP, which belongs to aggressive types of periodontitis with a continuous relapsing course. The RPP occurrence rate in Russia is $5-10 \%$ [1] and it has a tendency towards steady growth [2]. Unlike chronic periodontitis, where the microbial factor plays a key role, RPP is accompanied with a combined effect of three factors - the presence of specific periodontal pathogens; perverted immune response; genetic predisposition. Due to the complexity of the three-factors interaction, there is currently no single pathogenesis concept for RPP, which makes it difficult to diagnose and treat this nosology [3-5]. Nowadays, great importance in regulating periodontal tissues cell homeostasis belongs to the indicators $\mathrm{Ki}-67, \mathrm{Bcl}-2$ as well as the apoptosis index [6-9]. However, there is still no understanding of how these indicators change during RPP, including with comorbid conditions [10-18]. Immunohistochemical methods allow detecting more detail regarding the pathogenetic changes occurring through gingival
Article history:

Submitted 11 April 2019

Accepted 17 June 2019 epithelium cells renewal, their apoptotic elimination level, which will certainly expand the understanding of the pathogenetic processes underlying this disease, and will help improve diagnostics and treatment.

Aim of study: to identify the nature of gingival cell proliferation and apoptosis disturbances in patients with RPP.

\section{MATERIALS AND METHODS}

To achieve the set goal, an examination was conducted involving 60 people. The main group included 20 patients suffering from RPP, 20 virtually healthy persons with intact periodontium (control group), and 20 patients with chronic generalized periodontitis (comparison group).

Inclusion criteria - persons of both sexes aged 18-45 years with no severe somatic pathologies. The participants were examined following a standard scheme including an index assessment of the oral cavity hygienic status (Green J.C., Vermillion J.R., 1964), the severity of inflammation processes in periodontal tissues (Muhlemann, in the modification by Cowell R. et al., 1975, Flesar T.J., 1980), PMA (Parma, 1960), PI (Russel AL, 1956), and an X-ray examination.

Immunohistochemical and morphological examination of periodontal tissues was performed on biopsy specimens, at curettage, removal of mobile teeth and extraction of teeth subject to orthodontic indications. For the periodontal diseases morphological diagnostics, a biopsy of the gingival mucosa marginal edge and gingival papillae, was performed. The obtained stuff was fixed in a $10 \%$ formalin solution for 24 hours, after which it was washed under running water, dehydrated in alcohols with a gradual increase in the concentration, and embedded in paraffin. To conduct a review microscopy, deparaffined sections were stained with hematoxylin-eosin. When conducting immunohistochemical reactions, monoclonal mouse antibodies to Ki-67 protein (MB-1, Ventana) and Bcl-2 ((124) M. Cell, 1:200 dilution) were used. The study was carried out using a Ventana BenchMark XT device and an Optiview DAB IHC Detection Kit system. The images of $10-12$ visual fields were recorded with 
a MIRAXDESK digital camera (ZEISS) built into a Leica DM 1000 microscope tube (magnification $100 \times$ and $400 \times$ ), and transferred to a computer. The number of expressing nuclei of the $\mathrm{Ki}-67$ and $\mathrm{Bcl}-2$ genes was recalculated as per $1 \mathrm{~m}^{2}$ using the VidetestMorphology 4.0 morphometric software.

The cell proliferative activity was evaluated using the Ki-67 index, which was calculated by the formula below: $\mathrm{I} \mathrm{Ki}-67=\mathrm{X} / \mathrm{X}_{1} \cdot 100 \%$, where $\mathrm{X}_{1}$ is the number of nuclei immunopositive to $\mathrm{Ki}-67$, $\mathrm{X}$ is the total number of all the counted nuclei. A similar technique was employed when calculating the $\mathrm{Bcl}-2$ index: I Bcl-2 $=\mathrm{N} / \mathrm{N}_{1} \cdot 100 \%$, where $\mathrm{N}$ is the number of nuclei immunopositive to $\mathrm{Ki}-67, \mathrm{~N}_{1}$ is the total number of all the counted nuclei. Cell death through apoptosis was estimated through the apoptosis index, which was calculated using the following formula: Iapt $(\%)=\mathrm{Z} / \mathrm{Z}_{1} \cdot 100 \%$, where $\mathrm{Z}$ is the number of nuclei in apoptosis, $Z_{1}$ is the total number of nuclei.

\section{RESULTS AND DISCUSSION}

Studies of intact periodontium showed that proliferation (I Ki-67 (10.24 $\pm 0.72 \%)$, I Bcl-2 $(3.11 \pm 0.08 \%))$ dominate apoptosis $(0.51 \pm 0.07 \%)$, while having a low level of renewal and death of epithelial cells. In this case, low proliferation rates are balanced by low apoptosis activity.

In the comparison group, individuals with chronic periodontitis had an increased proliferative activity of gingival epithelial cells, which is evidence to the fact that the periodontal cells regenerative potential is high and their apoptotic activity remains moderate, while I Ki-67 is $20.31 \pm 0.34 \%$, IBcl- $2-5.92 \pm 0.04 \%$, and Iapt $-0.61 \pm 0.05 \%$. In the group of persons suffering from RPP, we observed a breakdown of the periodontal tissues adjustment mechanisms, which was expressed in the inhibition of IKi-67 (2.02 $\pm 0.44 \%)$, IBcl-2 (2.14 $\pm 0.51 \%)$, against an increase in the apoptosis index by 3 times $(1.53 \pm 0.38 \%)$. We have identified a direct correlation between the values of the OHI-S hygiene index and the apoptosis index, both in case of RPP and in chronic periodontitis; however, the statistical strength of this relationship with RPP $(\mathrm{r}=0.45)$ is weaker compared with chronic periodontitis $(r=0.91)(p<0.05)$; also, a direct correlation dependence of the PMA index with I apt $(r=0.720)$ and the reverse dependence with the proliferation index of $\mathrm{Ki}-67(\mathrm{r}=-0.501)(\mathrm{p}<0,05)$ was detected.

\section{CONCLUSION}

The study has shown that the development and progress of chronic periodontitis and RPP come accompanied by impaired cellular homeostasis. During the initial stages of inflammation in periodontal tissues, an increase in the cell proliferative activity was observed against virtually unchanged apoptosis index, which points at activated regeneration in the body; however, along with an increase in the tissues inflammation severity, there is a decrease in the epithelial cells proliferative potential as well as activation in their death manifested as apoptosis. In case of RPP, there is a breakdown of the periodontal tissues adjustment mechanisms, which reveals itself as inhibition of Ki-67 expression and an increase in the apoptosis index, which contributes to the progression of periodontal lesions inflammatory and destructive lesions.

\section{REFERENCES}

1. LeOnOva, E.V. Aggressive periodontitis: characteristics, clinic, diagnosis, treatment algorithms. Clinical observation / E.V. Leonova // Medi Publishing LLC. - 2018. - №1 (78). - P. 34-36. (In Russ.).

2. Genetically determined violation of mineral metabolism as a risk factor for the development of chronic generalized periodontitis with an aggressive course / V.G. Atrushkevich, A.V. Polyakov, A.I. Zinovieva [et al.] // Electronic Scientific and Educational Bulletin "Health and Education in the XXI Century". - 2012. - Vol.14, №5. - P. 28-29. (In Russ.).

3. GRUdyanov, A.I. Rapidly progressive periodontitis. Features of the clinical course / A.I. Grudyanov, IV. Bezrukova // Dentistry. - 2000. - T.79, No. 5. - P. 24-27. (In Russ.).

4. Grigorovich, E.SH. Cellular renewal of the gum epithelium in patients with chronic generalized periodontitis under the influence of the initial periodontal treatment / E.Sh. Grigorovich, R.V. Gorodilov, E.A. Zablotskaya // Institute of Dentistry. - 2011. - №2 (51). - P. 62-65. (In Russ.).

5. Osipova, Yu.L. Indicators of cell renewal and gum apoptosis in patients with rapidly progressive periodontitis. / Yu.L. Osipova, S.A. Akimova / Morphology. - 2018. - T. 153, №3. - P. 209-210. (In Russ.).

6. Study of molecular mechanisms of reparative regenerative processes in a wound during stimulation with chitosan / A.P. Vedyaeva, N.V. Bulkina, P.V. Ivanov, L.A. Zulkina / / Periodontology. - 2017. - №4 (85). P. 35-39. (In Russ.).

7. Osipova, Yu.L. Apoptosis of gum epithelial cells in normal and pathological conditions / Yu.L. Osipova., N.V. Bulkina, N.A. Harish // Morphology. - 2009. Vol. 136., №4. - P. 109. (In Russ.).

8. The role of violations of cell proliferation and apoptosis in the pathogenesis of inflammatory periodontal diseases in the background of gastroesophageal reflux disease / Yu.L. Osipova, N.V. Bulkina, M.A. Osadchuk, I.M. Kvetnoy // Saratov Journal of Medical Scientific Research. - 2013 - V.9, №3. - P. 449-453. (In Russ.).

9. Osipova, Yu.L. Optimization of complex therapy of chronic generalized catarrhal gingivitis / Yu.L. Osipova, N.V. Bulkina / Medical Council. - 2016. - №19. - P. 131-133. (In Russ.). 
10. Clinical manifestations of temporomandibular joint dysfunction in patients with free-end edentulous space / E.N. Pichugina, V.V. Konnov, N.V. Bulkina, T.V. Matytsina, M.V. Vorobeva, S.N. Salnikov, R.N. Mukhamedov, V.A. Mikailova, I.V. Matysina // Archiv EuroMedica. - 2019. - Vol. 9, № 1. - P. 175-176. https://doi.org/10.35630/2199-885X/2019/9/1/175

11. Causes behind distal occlusion / M.V. Vorobieva, V.V. Konnov, N.V. Bulkina, A.A. Bizyaev, D.N. Maslennikov, A.S. Khodorich, E.S. Popko, S.V. Konnov, I.V. Matytsina // Archiv EuroMedica. - 2019. - Vol. 9, № 1. - P. 191-193. https://doi.org/10.35630/2199$885 \mathrm{X} / 2019 / 9 / 1 / 191$

12. Morphofunctional changes in temporomandibular joint correlating with its morphological variations in patients with dentition defects complicated by distal occlusion / V.V. Konnov, A.P. Vedyaeva, D.Kh. Razakov, E.N. Pichugina, T.V. Matytsina, S.N. Salnikova, M.V. Vorobeva, R.N. Mukhamedov, I.V. Matysina // Archiv EuroMedica. - 2019. - Vol. 9, № 1. - P. 52-58. https://doi.org/10.35630/2199-885X/2019/9/1/52

13. Temporomandibular joint morphology at orthognatic bite / A.R. Arushanyan, V.V. Konnov, A.P. Vedyaeva, D.Kh. Razakov, T.V. Matytsina, D.N. Maslennikov, R.N. Mukhamedov, A.S. Khodorich, I.V. Matysina // Archiv EuroMedica. - 2019. - Vol. 9, № 1. - P. 18-19. https://doi.org/10.35630/2199-885X/2019/9/1/18

14. BASOv A.A., IvChenko L.G., Domenyuk D.A., DMitrienko T.D., NuZhnaYa C.V. The role of oxidative stress in the pathogenesis of vascular com- plications in children with insulinable sugar diabetes. Archiv EuroMedica, 2019; 9(1): 136-145. https://doi. org/10.35630/2199-885X/2019/9/1/136

15. Davydov B.N., Domenyuk D.A., DMitrienko S.V. Peculiarities of microcirculation in periodont tissues in children of key age groups sufficient type 1 diabetes. Part I. Periodontology, 2019; Vol. 24; 1-24(90): 4-10. DOI: 10.25636/PMP.1.2019.1.1

16. Davydov B.N., Domenyuk D.A., DMitrienko S.V. Peculiarities of microcirculation in periodont tissues in children of key age groups sufficient type 1 diabetes. Part II. Periodontology, 2019; Vol. 24; 2-24(91): 108-119. DOI: 10.33925/1683-3759-201924-2-108-119

17. Davydov B.N., Domenyuk D.A., BYkov I.M., IVChenko L.G., DMitrienko S.V. Modern possibilities of clinical-laboratory and $\mathrm{x}$-ray research in preclinical diagnostics and prediction of the risk of development of periodontal in children with sugar diabetes of the first type. Part I. Periodontology, 2018; Vol. 23; 3-23(88): 4-11. DOI:10.25636/PMP.1.2018.3.1

18. Kulikova N.G., Domenyuk D.A., Zelensky V.A., TKachenko A.S. Evaluation of the effectiveness of pharmaco-physiotherapeutic treatment of catarrhal gingivitis on the results of the condition of mucosal immunity of oral cavity in women in the postpartum period. Medical Bulletin of the North Caucasus. 2017; Vol. 12; 4: 417-421. (In Russ., English abstract). DOI: 10.14300/mnnc.2017.12117. 